\title{
Cell labeling with magnetic nanoparticles: Opportunity for magnetic cell imaging and cell manipulation
}

\author{
Jelena Kolosnjaj-Tabi ${ }^{1,2}$, Claire Wilhelm", Olivier Clément ${ }^{2}$, Florence Gazeau ${ }^{1 *}$ \\ From Nanophysics for Health \\ Mittelwhir, France. 5-9 November 2012
}

\begin{abstract}
This tutorial describes a method of controlled cell labeling with citrate-coated ultra small superparamagnetic iron oxide nanoparticles. This method may provide basically all kinds of cells with sufficient magnetization to allow cell detection by high-resolution magnetic resonance imaging (MRI) and to enable potential magnetic manipulation. In order to efficiently exploit labeled cells, quantify the magnetic load and deliver or follow-up magnetic cells, we herein describe the main requirements that should be applied during the labeling procedure. Moreover we present some recommendations for cell detection and quantification by MRI and detail magnetic guiding on some real-case studies in vitro and in vivo.
\end{abstract}

High-resolution magnetic resonance imaging (MRI) cellular MRI, magnetic nanoparticles, magnetic cell labeling, magnetic vectorization

\section{Rationale}

Magnetic labeling provides living cells with new features, which allow cell magnetic resonance imaging (MRI), enable distal cell manipulation applicable to tissue-engineering techniques, or could be even used for magnetically assisted cell delivery to target organs in vivo. Among magnetic nanoparticles, superparamagnetic iron oxide nanoparticles have an extensively documented background about particle synthesis and surface modification. Moreover, if properly used (i.e. when well dispersed), such particles do not alter viability, function, proliferation or differentiation of cells. In order to efficiently and safely label different cell types, including stem cells, this tutorial presents a well-established method of controlled cell labeling with citrate-coated ultra small superparamagnetic iron oxide nanoparticles (herein referred to as magnetic nanoparticles - MNP). In addition, we also provide a method of detection and quantification of single cells with high resolution MRI

\footnotetext{
*Correspondence: claire.wilhelm@univ-paris-diderot.fr; florence.gazeau@univparis-diderot.fr

'Laboratoire Matière et Systèmes Complexes, UMR 7057, CNRS and Université Paris Diderot, France

Full list of author information is available at the end of the article
}

and describe the basis of cell sorting and magnetic manipulation for engineering and therapeutic purposes.

\section{Cell labeling with magnetic nanoparticles Background}

Different strategies can be applied in order to endow cells with sufficient magnetization to be detectable by MRI and/or to be manipulated by an external magnetic field. The handiest way is the co-incubation of cells with magnetic nanoparticles, where the particles are generally internalized through the spontaneous endocytosis pathway [1] or phagocytosis [2]. However cellular uptake may strongly depend on nanoparticle properties, especially on surface functionalization [3]. While dextran-coated nanoparticles show very poor uptake due to steric repulsions between particles and cell membrane, the best strategy to facilitate endocytosis of nanoparticles is to favor a specific binding or non-specific adsorption to the cell membrane. This can be achieved by linking biological effectors on nanoparticles such as antibodies, transferrin or HIV-Tat peptide that target specific receptors on plasma membrane [4]. The use of cationic transfection agents that form highly charged complexes with nanoparticles is also efficient to trigger cellular uptake, but usually requires long incubation times 
(>6 hours) [5]. Moreover the aggregation state of nanoparticles in the formed complexes cannot be controlled.

\section{The importance of nanoparticle stability in cell labeling medium}

As the cells react in a different manner depending on whether the nanoparticles remain dispersed in suspension or become aggregated, the stability of MNPs is a key issue to achieve an efficient and controllable magnetic labeling. Moreover, cell toxicity might arise from MNPs aggregates, whereas the same MNPs would have no deleterious effect when correctly dispersed. In addition, the surface properties of nanoparticles can be changed upon dynamic adsorption of the proteins and macromolecules encountered in the biological medium. Therefore what the cell perceives is not the original nanoparticle designed by a chemist, but a modified heterogeneous surface reconfigured by the biological milieu [6,7]. Both the physical state (aggregated versus isolated nanoparticles) and the biological identity of particles (comprising the adsorbed proteins) dictate the uptake by different cell types and the in vivo biodistribution of nanoparticles.

\section{Practical aspects of cell labeling}

Labeling cells in vitro offers the opportunity of controlling cell interactions with nanoparticles (Figure 1). In this tutorial we describe a simple and straightforward method to magnetically label virtually all cell types in a rapid, predictive and quantitative way. The objectives and requirements for an efficient cell labeling are summarized in Figure 2 and the key steps in the labeling procedure are shown on Figure 3. Our method uses citrate-coated maghemite nanoparticles of 7-8 $\mathrm{nm}$ in diameter. Small citrate ligands on the surface of the iron oxide confer negative surface charges to the particles, which are stabilized by electrostatic repulsions in water or serumfree culture medium. We use serum-free culture medium to avoid adsorption of proteins on the nanoparticles that could affect both their stability and their affinity for the cell membrane. Moreover the stability of citrate-coated particles (measured through their hydrodynamic size) can be modulated by controlling the concentration of free citrate ions: the nanoparticles remain isolated in culture medium supplemented with $5 \mathrm{mM}$ free citrate, while they aggregate in citrate-free medium and eventually form

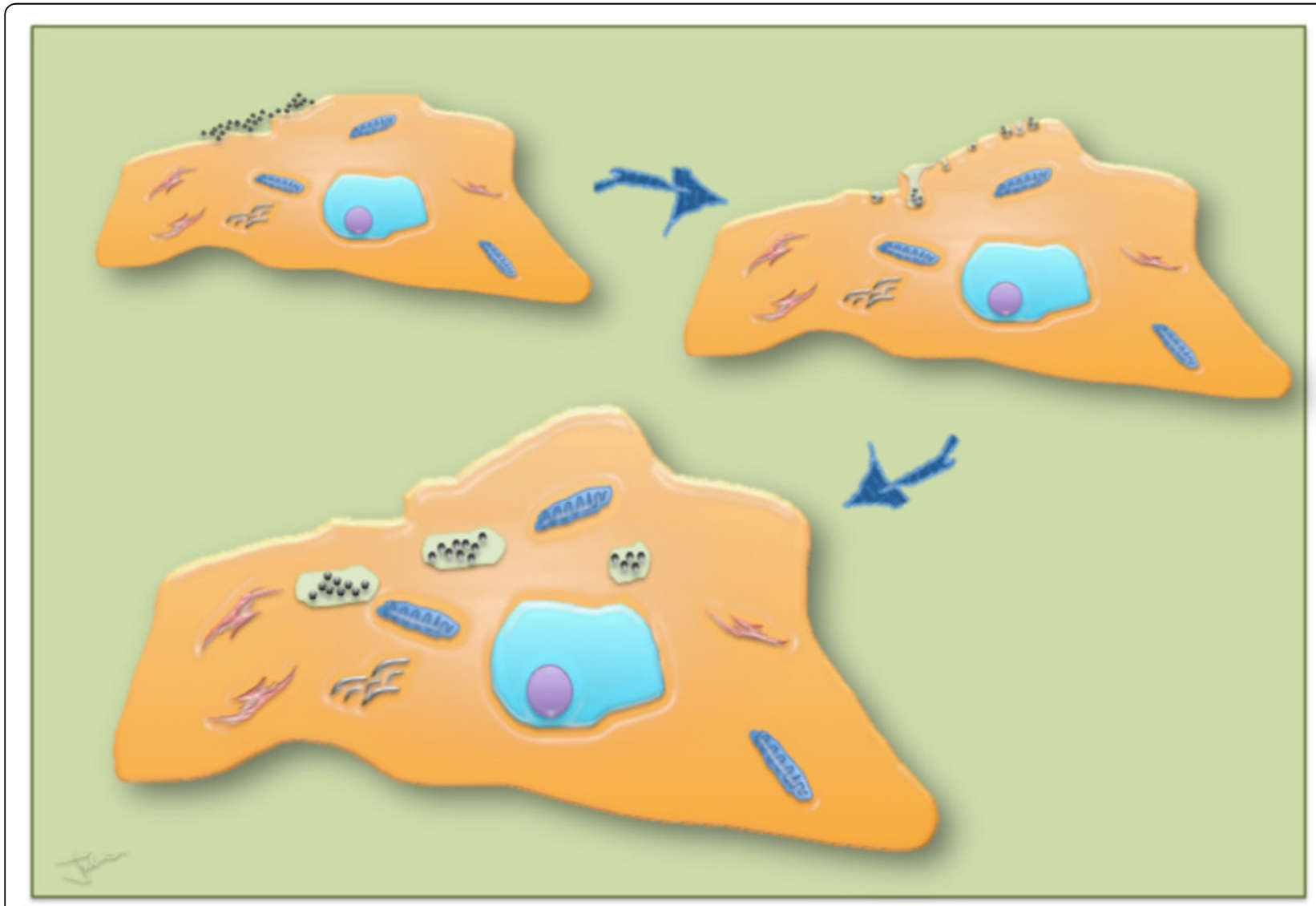

Figure 1 Schematic representation of cell interactions with nanoparticles. Particles first adsorb on plasma membrane, which consequently undergoes invagination. The MNP-loaded vesicles then pinch off the membrane and subsequently fuse with endosomes and lysosomes, which are dispersed within the cell's cytosol. 


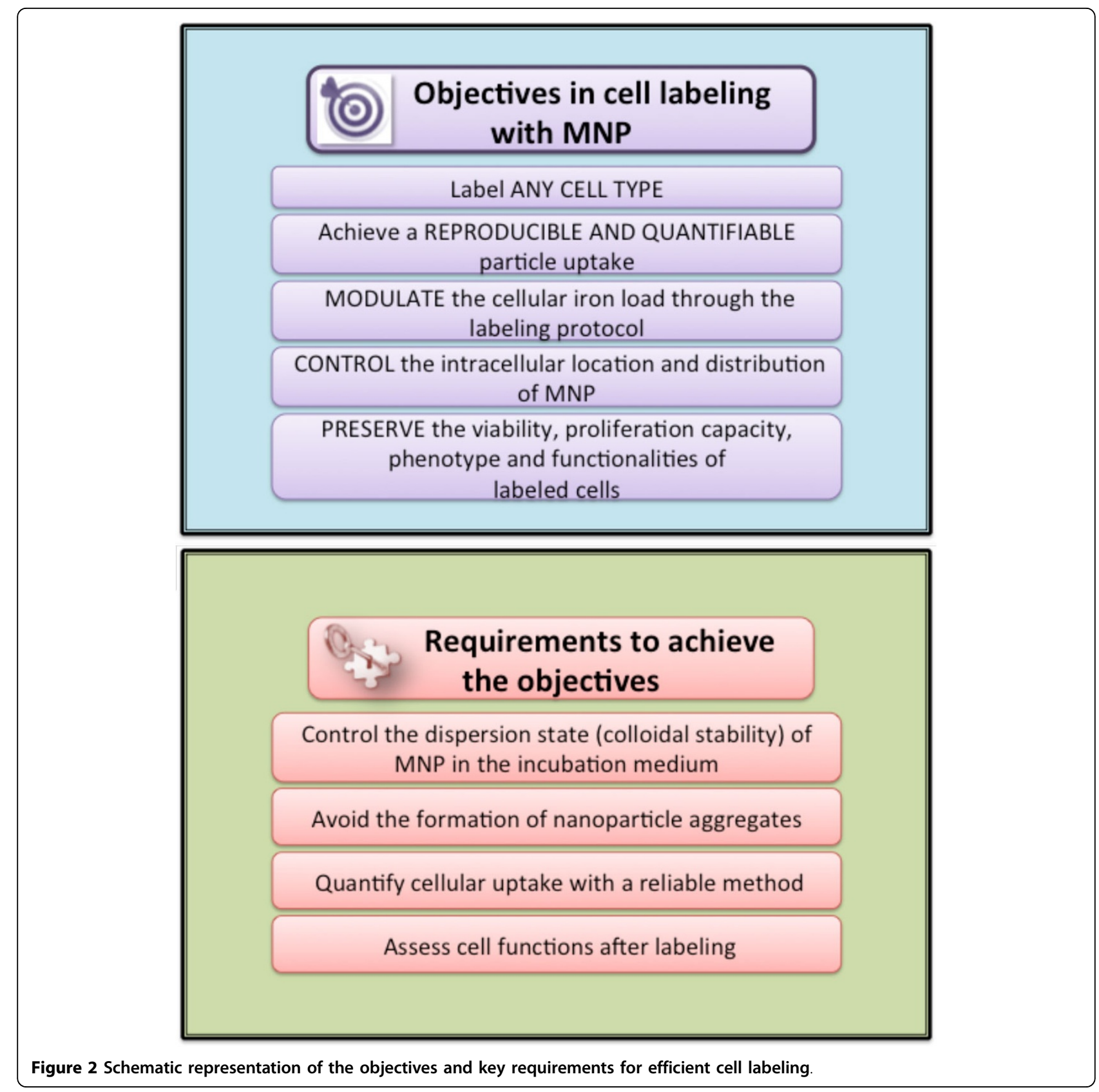

chains when submitted to a magnetic field [8] (Figure 4). Thus, to avoid MNP aggregation, cell labeling should be performed in the serum-free medium supplemented with citrate. While appropriate labeling conditions preserve the homeostasis of cells, failure to provide optimal labeling conditions might lead to particle aggregation (Figure 4) that might have a negative impact on the cells.

After a short incubation time (typically less than one hour, compared to several hours of cell labeling with other types of magnetic nanoparticles), cells are rinsed with the citrate-enriched, serum-free medium and left for particle chase in the standard cell medium at $37^{\circ} \mathrm{C}$.
Once the chase period is over, cells appearance should be attentively examined. The main qualitative check points are summarized in Figure 3.

\section{Mechanistic aspects in cell labeling with MNPs}

The uptake of dispersed citrate-coated MNPs consists of a two-step process. The first step is the non-specific adsorption of particles on the plasma membrane, following a generic Langmuir kinetics. This step can be investigated separately if cells are maintained at $4^{\circ} \mathrm{C}$, thus inhibiting the internalization process. Remarkably the affinity of MNPs for cell membrane does not depend on cell type 


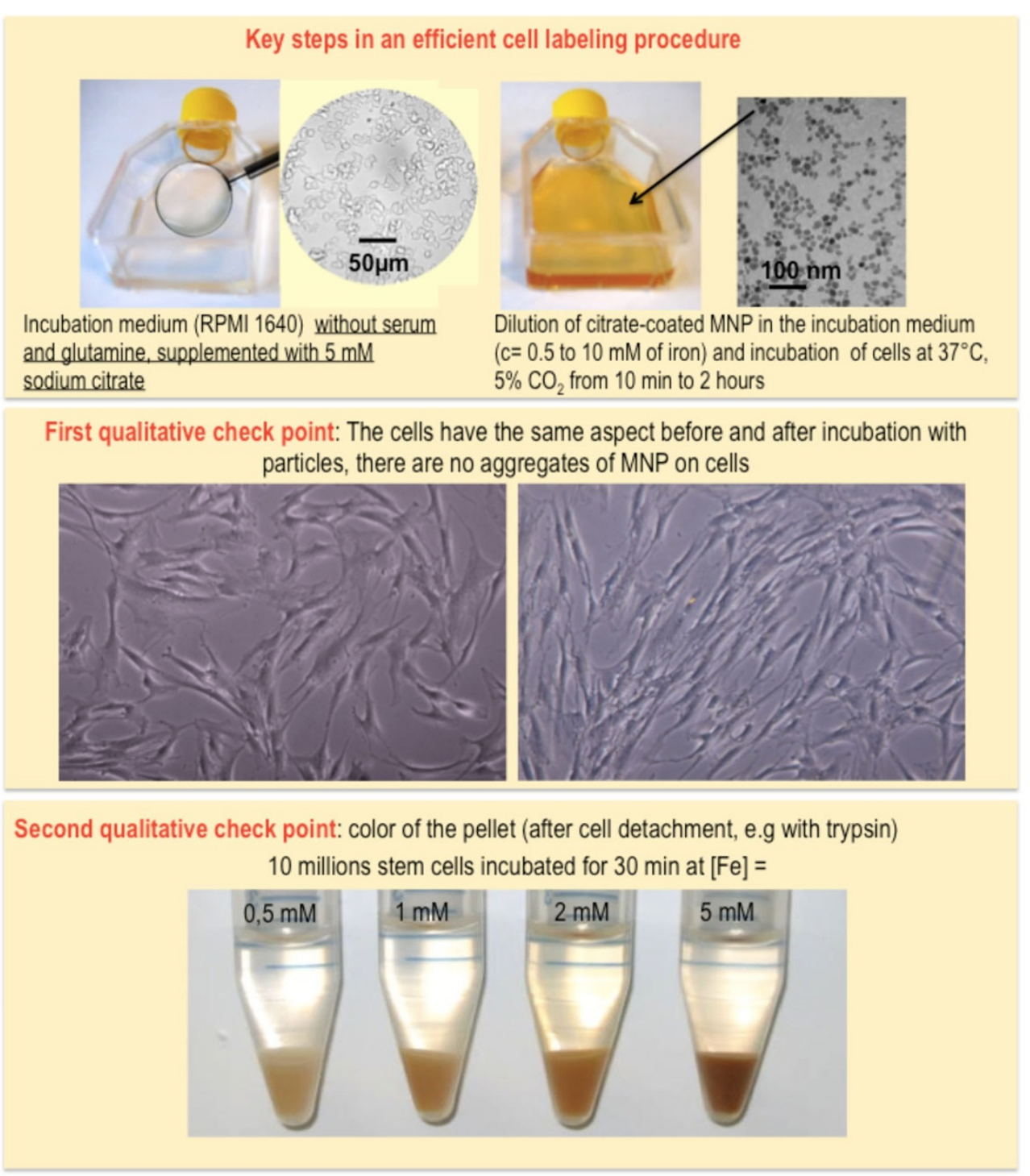

Third qualitative check point: imaging after Perls (Prussian blue) staining, used to reveal the presence of cellular iron (blue dots)
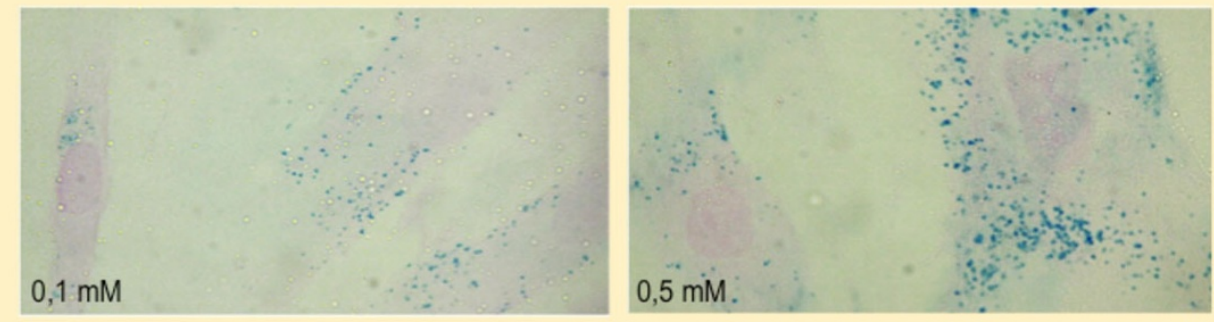

Figure 3 Labeling procedure and its qualitative checkpoints to assess labeling efficacy. The figure represents the key steps for efficient cell labeling. The checkpoints include the evaluation of cell outlook (color, shape, presence of aggregates).

$\left(1.6-4 \times 10^{7} \mathrm{M}^{-1}\right)$ and the binding capacity (typically 0.03 $\mathrm{pg} / \mu \mathrm{m}^{2}$ or $2.4 \times 10^{4}$ nanoparticles $/ \mu \mathrm{m}^{2}$ ), but it only depends on cell size [9]: the larger the cell, the higher the number of nanoparticles adsorbed on plasma membrane.
The second step involves the internalization of the plasma membrane, which invaginates, encloses the nanoparticles into vesicles, and delivers them into intracellular compartments, successively to early endosomes, late 


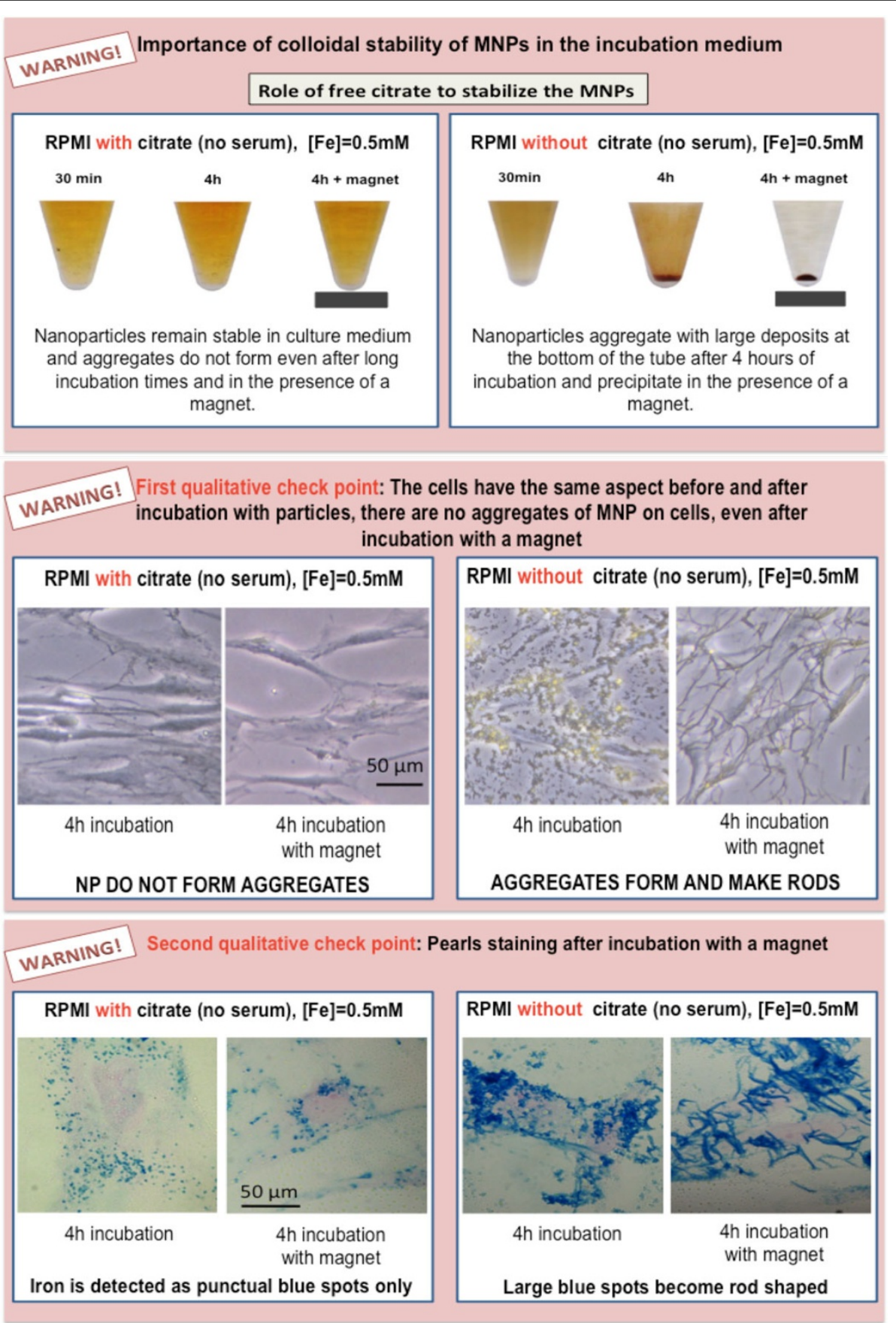

Figure 4 Comparison of examples of appropriate and inappropriate labeling conditions due to aggregation of anionic magnetic nanoparticles.

endosomes and ultimately to lysosomes (Figure 5). At $37^{\circ}$ $\mathrm{C}$ both the particles adsorption and internalization occur concomitantly. Moreover, the binding sites on plasma membrane are continuously recycled, allowing continuous internalization. As the internalization capacity and the internalization time are conserved for different cell types (with the exception of macrophages), this model allows predicting quantitatively the cellular uptake and optimizing the labeling procedure in terms of incubation time and extracellular iron concentration.

\section{Intracellular storage of internalized particles}

Intralysosomal sequestration of MNPs has the advantage to protect the cell from the release of any free toxic iron 


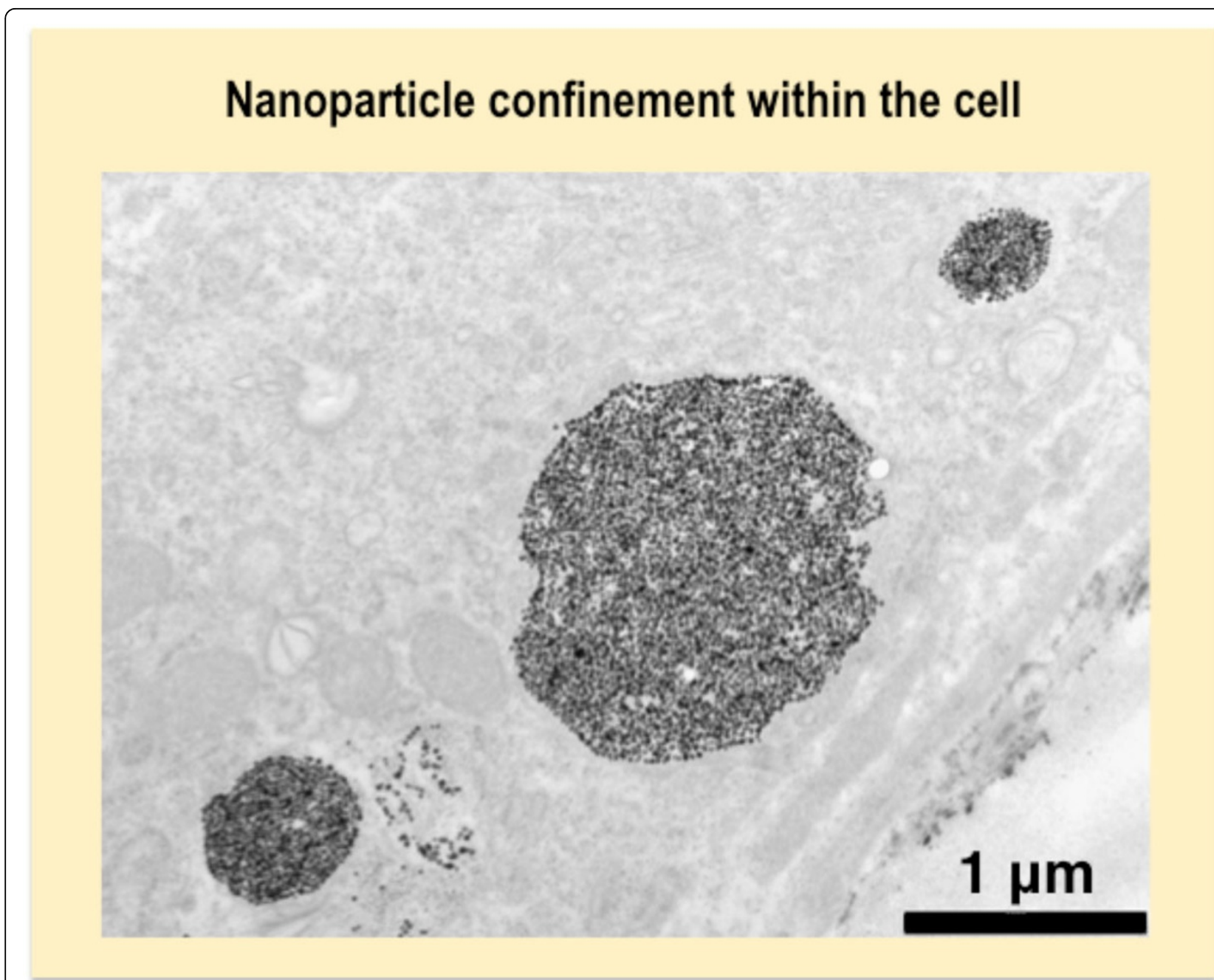

Figure 5 Transmission electron micrograph of a cell loaded with magnetic nanoparticles, which are confined in endosomes or lysosomes.

species in the cytoplasm. Moreover the lysosomes are used by cells to metabolize MNPs and to degrade them at long term [10,11]. Likewise the in vivo biotransformation of MNPs occurs intracellularly within the lysosomes, and the iron, coming from the degradation of MNPs, is locally transferred and stored within the ferritin, the iron storage protein $[12,13]$.

\section{Impact of magnetic nanoparticles on cell viability}

Indeed, one of the significant aspects in cell labeling is also the assessment of cell functions after MNP internalization. Prior to the use of magnetically labeled cells for imaging and therapeutic purposes, functional tests have to be performed in order to check the innocuousness of magnetic labeling on cell viability, cell proliferation, cell phenotype and specific functionalities. Cell viability can be assessed by different assays, which may determine different cell characteristics, such as the integrity of cell membrane, mitochondrial activity, apoptosis, etc. While there are no special recommendations on which tests to use after MNP labeling, we should compare results from the same kind of assay if we are comparing viabilities of different cells. Cell proliferation should be monitored over a period of at least 5 days [9]. The preservation of cell functions and differentiation capacities might differ among distinct cell types, therefore should be determined specifically. The expression of specific genes of interest can also be quantified to assess subtle phenotypical alterations following SPIO labeling [14,15]. An example is given in Figure 6[8].

To date different cell types have been labeled with MNPs (immune cells, endothelial cells, cancer cells, primary culture or established cell lines and progenitors cells, to mention just a few) and detrimental effects on cell proliferation and cell functions at short and long terms, in vitro or in vivo, were not observed [9]. The labeling of stem cells is 


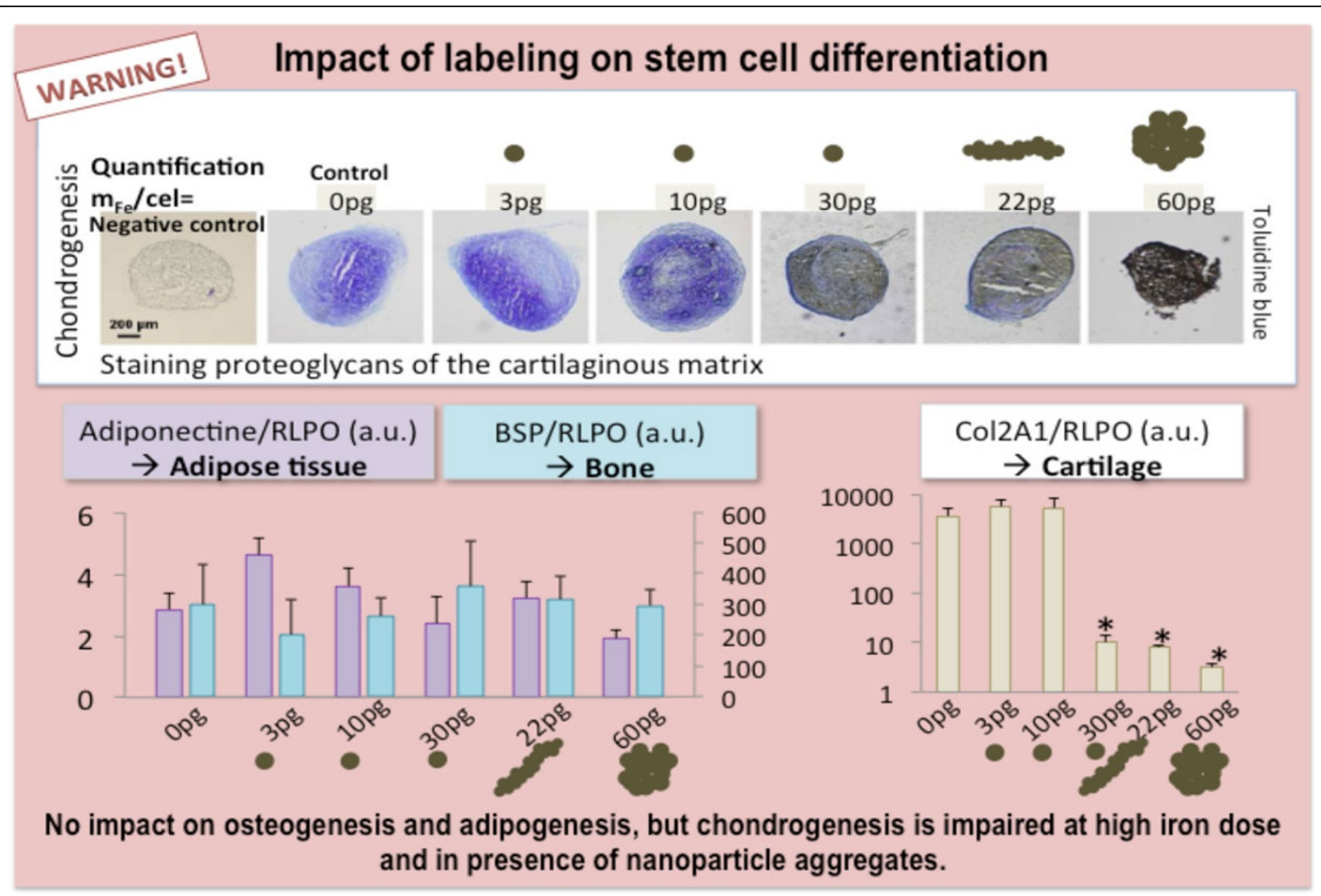

Figure 6 Example of monitoring of cell functions after mesenchymal stem cell labeling. The figure is adapted from reference (8) and shows cell differentiation ability. In the represented case, after labeling, cell differentiation to adipose or bone cells is not impaired at high MNPs concentration. In contrast, high MNP load impacts cartilage formation.

more tricky as these cells should conserve their selfrenewal and multipotency after internalization of MNPs [16]. Human neural precursor cells were also efficiently labeled without impairment of their differentiation capacity $[17,18]$. However in some studies using transfection agents for cell labeling, controversial effects were observed on the multilineage differentiation capacity of mesenchymal stem cells. The chondrogenesis (i.e. the capacity to differentiate in cells of cartilage) was partially inhibited in one study [19], but not in others [14,20-22], whereas adipogenesis and osteogenesis were not impaired. On the contrary, while labeling cells with citrate-coated MNP, we could modulate the amount and the physical state of nanoparticles interacting with cells and could conclude that only high dose of MNPs or an aggregated state, could have adverse effects on cell differentiation (chondrogenesis) [8] (Figure 6). Labeling conditions with perfectly stable MNP is thus recommended for use in cell therapy assays.

Fate of the particles in a living cell

During the division process, the cell shares the magnetic endosomes between its two daughter cells. The iron load is thus reduced by a factor of two at each division. In normal conditions, there is no exocytosis of MNPs. However, under stress conditions, some magnetically labeled cells can release nanoparticle-loaded microvesicles in the extracellular medium $[23,24]$. These cell-released vesicles can transfer nanoparticles to other naïve cells [24], especially macrophages [25]. This process, if confirmed in vivo, could participate to a horizontal intercellular transfer of nanoparticles, challenging to some extent the initial specificity of cell labeling [26,27].

\section{Quantification of iron load}

Once the chase period is over, cells appearance should be attentively examined. Check points are summarized in Figure 3. After our first qualitative examinations (Figure 3), we should proceed with the quantification of iron load. Currently there are several methods for iron dosage in cells, namely, the elemental analysis, the electron paramagnetic resonance (a method which relies on magnetism and allows the differentiation between superparamagnetic iron from the particles and endogenous iron bound in ferritins, the iron storing proteins) $[12,28]$ and the colorimetric 
analysis, to mention just a few. Apart from these methods that are generally applied to the cell pellet, other single cell iron assessments can be also performed. Something of the kind is the single cell magnetophoresis [28]. This method also relies on magnetism and is schematized in Figure 7.

\section{Cell responsiveness to the magnetic forces}

As lysosomes in labeled cells concentrate several millions of MNPs, a labeled cell becomes responsive to an inhomogeneous magnetic field, generated, for example, by a permanent magnet. In a non uniform magnetic field B, defined by an unidirectional magnetic field gradient gradB, a labeled cell experiences a magnetic force $M(B)$ $\operatorname{gradB}$, where $M(B)$ is the magnetic moment of the cell in the field $B$ (equal to the magnetic moment of one MNP multiplied by the number of MNPs per cell). Typically a permanent magnet generates a magnetic field gradient of $10-50 \mathrm{~T} / \mathrm{m}$ over a distance of approximately $1 \mathrm{~cm}$. The corresponding force experienced by the cell (with an average iron load of $10 \mathrm{pg}$ ) may vary from $1 \mathrm{pN}$ to a few $\mathrm{nN}$ [29]. For cells in suspension, the magnetic force is balanced by the viscous force $6 \pi \eta R V$, where $\eta$ is the viscosity of the medium, $\mathrm{R}$ the cell radius and $\mathrm{V}$ the cell velocity. In a set-up with calibrated B and gradB (18 T/ $\mathrm{m})$, it is easy to deduce iron load from the determination of $\mathrm{V}$ and $\mathrm{R}$ for each cell by video-microscopy (Figure 7 top). From this experiment we can thus determine the distribution of MNP uptake in a cell population (Figure 7 middle). If the cells have not been labeled in the appropriate way (and are consequently covered with particle aggregates and cellular debris), magnetophoresis will not reflect the cell velocity that is due to intracellular iron, but will indicate the velocity that is due to internalized and membrane-attached nanoparticles. Besides, as we can see on Figure 7 (bottom), chains of aggregates that are not attached to cell membranes also migrate towards the magnet. In contrast to other global dosage of iron load in cell pellet, single cell magnetophoresis allows to visualize potential artifact linked to nanoparticle aggregation. The control of nanoparticle stability is once again the critical point to achieve a quantifiable and reproducible magnetic labeling.

\section{Imaging cells with magnetic resonance imaging (MRI)}

Cell tracking in vivo: the advantages of MRI

One of the new emerging applications of magnetic cell labeling concerns magnetic resonance cell tracking. Magnetic resonance imaging (MRI) allows real-time wholebody examinations with excellent soft-tissue contrast and spatial resolution. Moreover, impactful development has been made on high-field MR scanners, magnetic gradient systems and radiofrequency (RF) coils [30]. One of the new coils, such as the cryogenic probe, allows submilimetric resolution and gives the means to perform cellular MRI in vivo. The advantage of the cryogenic probe to improve the signal-to-noise (SNR) ratio and concomitantly improve the image resolution, has been demonstrated throughout the last decade in several studies [30,31].

\section{Iron oxide nanoparticles as cellular MRI contrast agents}

In order to be distinguished from tissues, the cells have to be labeled with a contrast agent (Figure 8). Iron oxide nanoparticles are potent MR contrast agents that can positively or negatively enhance the signal, depending on particle concentrations and applied MR sequence [32]. The particles are characterized by their $\mathrm{r} 1$ and $\mathrm{r} 2$ relaxivities, which indicate the ability to increase the longitudinal and transverse relaxation rate of proton magnetization per $\mathrm{mM}$ of agent. Nevertheless, when MNPs are internalized into endosomes or lysosomes, their contrast properties radically change [33]: their longitudinal relaxivity is strongly diminished due to poor accessibility of water protons among highly concentrated nanoparticles tightly packed in endolysosomal compartments. Once within the intracellular compartments, magnetic interactions between MNPs also likely play a role in relaxivity variations, increasing the $\mathrm{r} 2 / \mathrm{r} 1$ ratio after cell internalization [34]. An important consequence is that a magnetized cell creates a strong localized magnetic inhomogeneity in the uniform magnetic field of the MR scanner. Typically the field increment is about $10^{-4} \mathrm{~T}$ at the surface of a cell (loaded with approximately $5 \mathrm{pg}$ of iron) and falls to $10^{-7} \mathrm{~T}$ at a distance of $50 \mu \mathrm{m}$ from the cell [33]. This cell-induced magnetic artifact (Figure 9) can be detected with susceptibility weighted imaging or T2* weighted gradient echo sequences. Consequently, when spatial resolution is sufficiently high (typically less than $100 \mu \mathrm{m}$ ), single magnetic cells appear as focal signal voids. Single cell detection has been proven using high field MRI [33] or the clinical $1.5 \mathrm{~T}$ scanner equipped with a low noise superconducting coil [35]. As an example, Figure 10 shows high-resolution MR scans of agarose gels containing different numbers of individualized magnetically labeled cells, obtained at $4.7 \mathrm{~T}$ with a scanner provided with a cryogenic probe [31]. At low density, each signal void can be associated to one single cell. Indeed, the apparent cell size, detected by MR, is larger than the actual size of the cell and depends on the parameters of the MR sequence (Figure 9).

\section{Cell imaging in cell therapies}

Cell tracking by MRI has become a method of choice to evaluate cell therapies, which involve direct (local or intravenous) administration of labeled cells (Figure 11). At high cell densities (local injections), isolated cells can be hardly detected, but we can observe a global signal loss, which is less dependent on MRI parameters 


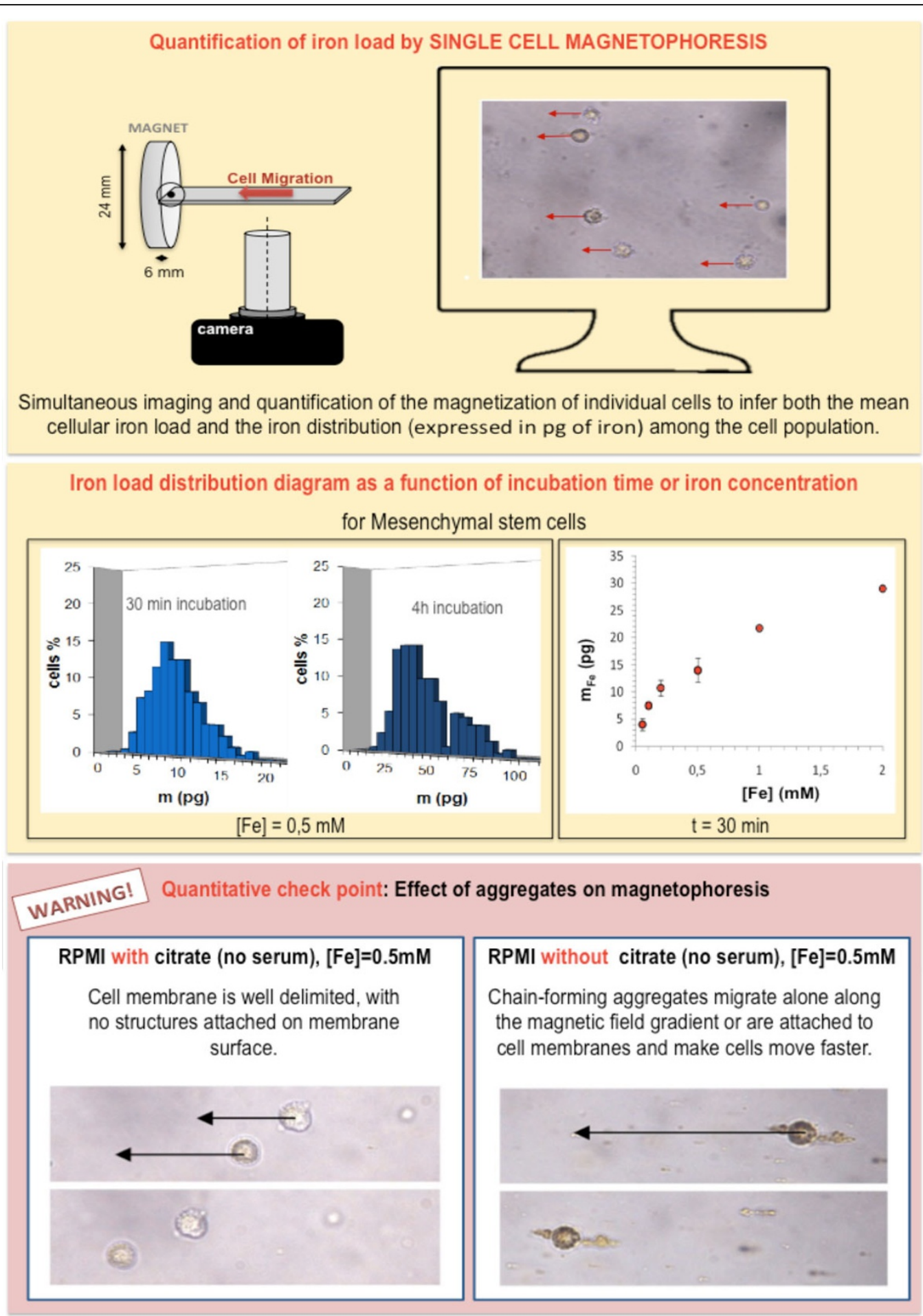

Figure 7 Single cell magnetophoresis. Schematic representation of the magnetophoresis setting (top) and iron load distribution diagrams (middle) obtained by the magnetophoresis experiment, presented as iron load as function of time or as function of iron concentration in the cell culture medium. When magnetophoresis is performed on cells that have not been correctly labeled, the outcome of the assay does not reflect the correct value of the intracellular iron load (as the obtained value is higher due to extracellular aggregate pods). 


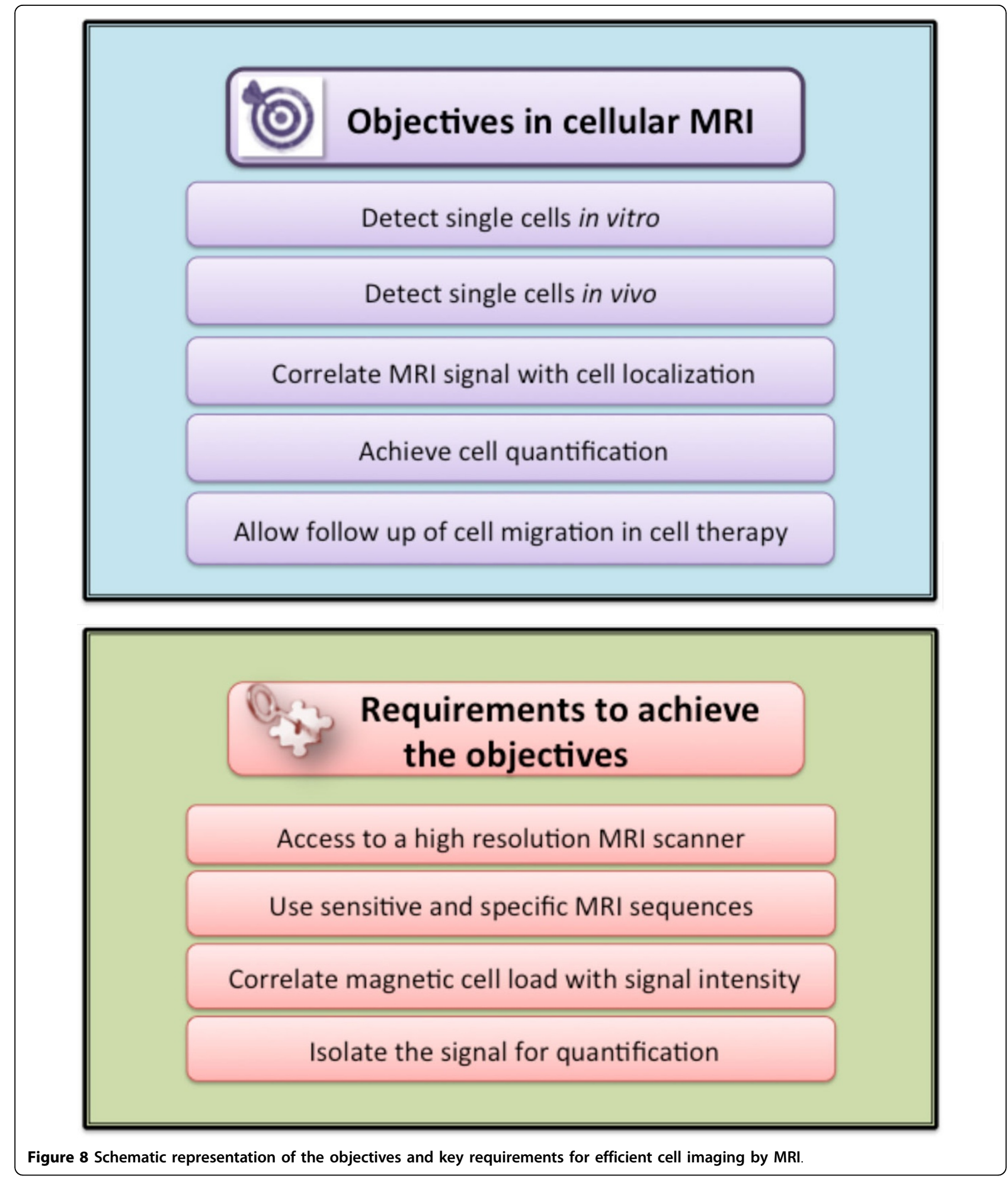

(Figure 11). In a pioneering study using cellular MRI in vivo, MRI could be used to monitor the migration of lymphocytes injected intravenously to tumor bearing mice [36]. Lymphocytes were targeted to tumor cells through immune recognition, where the MRI showed a complex cell migration pathway. Lymphocytes first homed to the spleen to multiply and become activated, and only after multiplication they infiltrated the tumor and made it regress. This study was important from a methodological point of view, showing, for the first 


\section{Proton magnetization around the cell: the dephasing effect}
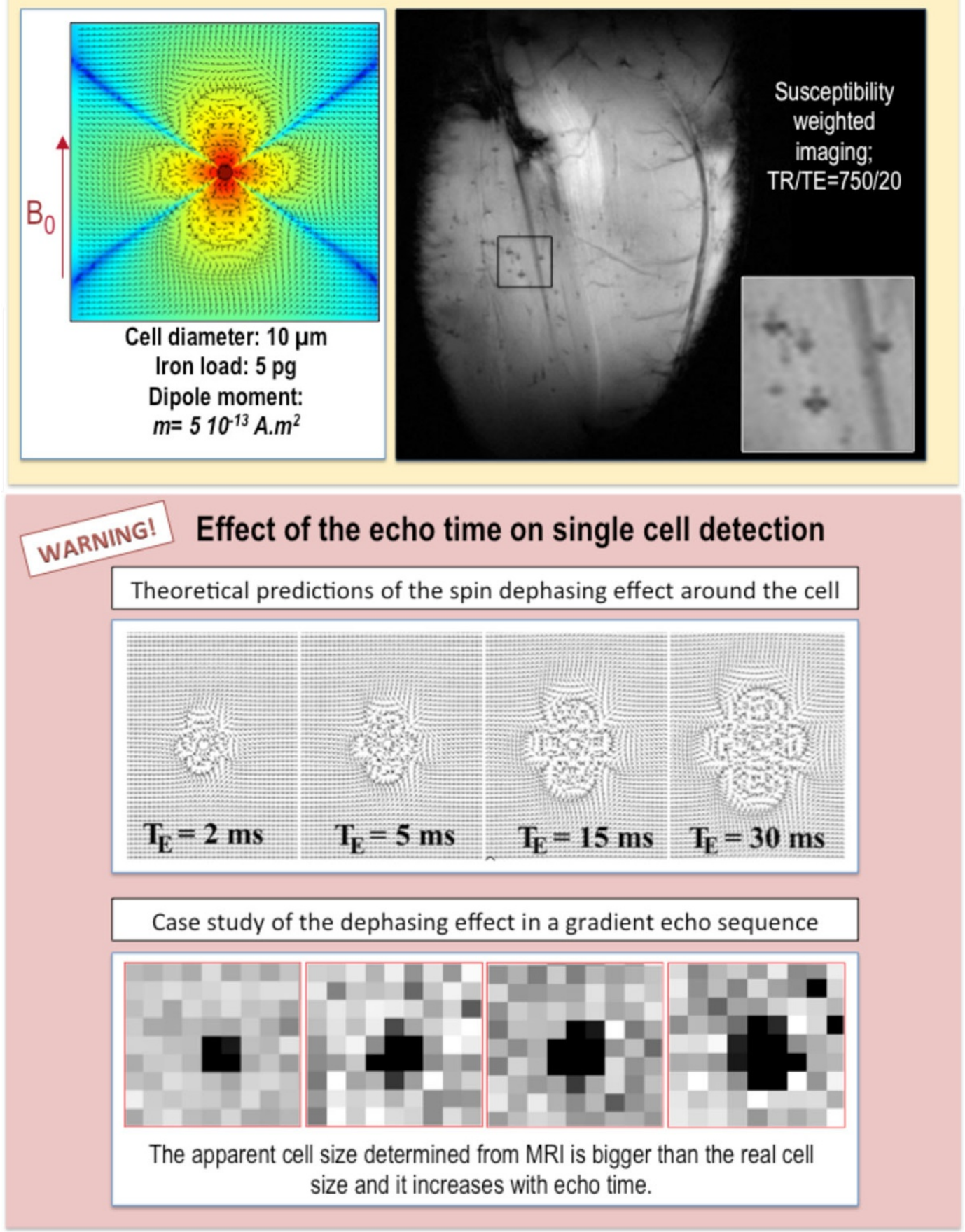

Figure 9 The MR dephasing effect. Theoretical and real case study of the dephasing effect of protons in the vicinity of a labeled cell in vivo. The upper panel shows the MR image of the lower hind limb of a mouse, intravenously injected with magnetically labeled macrophages, which form a typical four-lobed clover in the susceptibility-weighted scan (in-plane resolution of $39 \mu \mathrm{m}$ ), obtained with a $4.7 \mathrm{~T}$ scanner provided with a dedicated cryogenic probe. The bottom panel points out the impact of the echo time on the apparent cell size (top theoretical predictions and bottom real case study obtained at 9.4 T). The bottom panel has been adapted from reference (46). 


\section{Detection and quantification of single cells using the cryogenic probe and 4.7T MRI as function of labeling conditions}
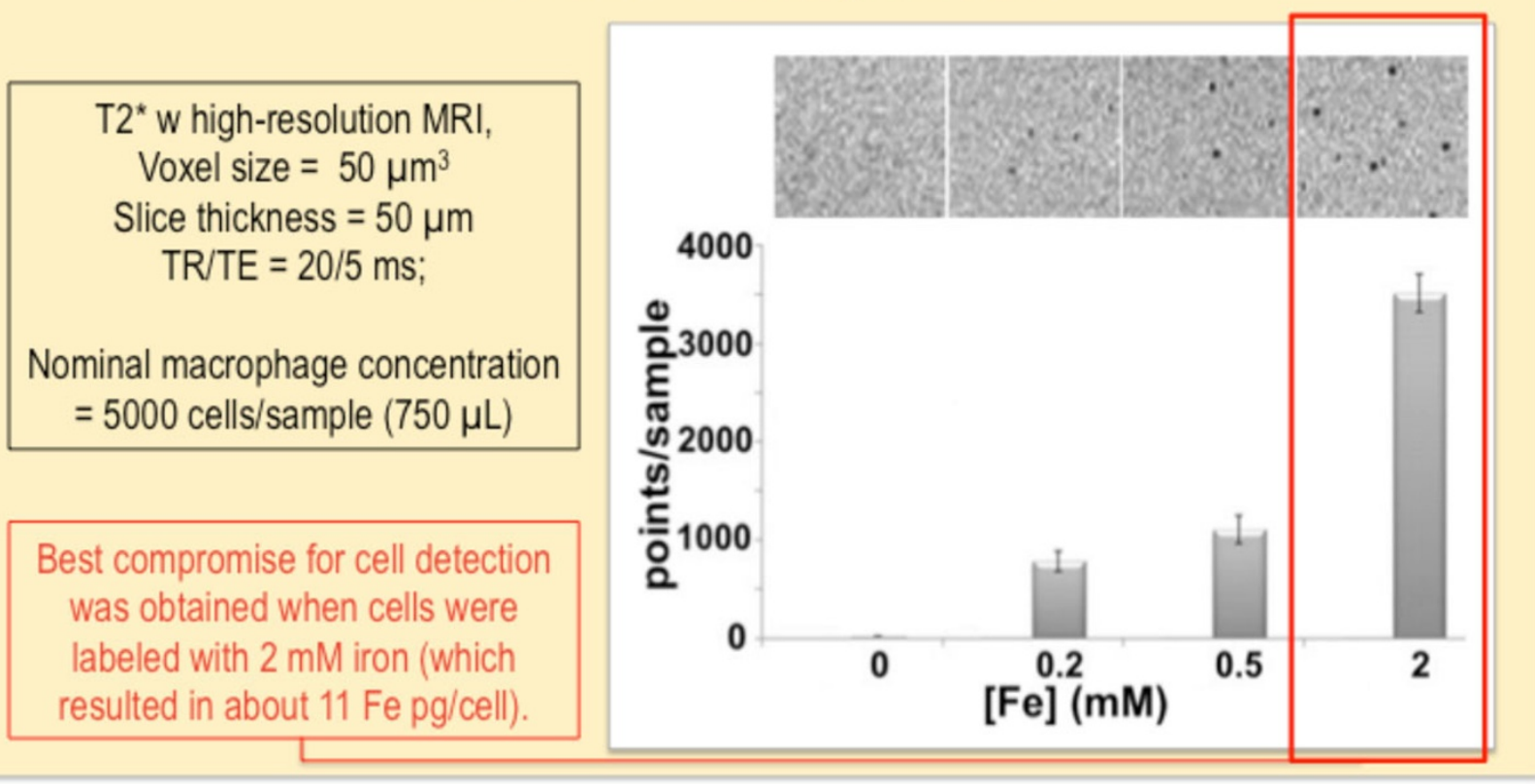

Figure 10 Cell detection as function of labeling conditions. A case study of agarose phantoms spiked with the same amount of cells, labeled with ascending concentrations of iron. The images were obtained with a T2* weighted gradient echo sequence, with a $4.7 \mathrm{~T}$ scanner provided with a dedicated cryogenic probe. The figure is adapted from reference (31).

time, that single cells could be detected by MRI directly in vivo in a tumour [36]. This was extremely challenging, as lymphocytes were poorly labeled after several divisions in the spleen (and cell iron mass fell below 0.2 $\mathrm{pg}$ ) and the imaging was made on a clinical $1.5 \mathrm{~T} \mathrm{MR}$ scanner. Together with many other studies by different groups, we can realize that MRI offers a great potential for cell tracking, which is also progressively being integrated in clinical assays. Be that as it may, despite the fact that MRI might provide us with real-time insight in cell distribution in vivo, we should corroborate its results with other, even post-mortem methods of cell detection, such as histology.

\section{Quantification of punctual signal voids}

In order to quantify detected signal voids that might correlate to administered magnetic cells, we should proceed with image processing and (automatic) dot count. In MR image processing, highly precise dot quantification remains very complex especially in vivo where several tissular structures might impact the dot count. However a good approximation can be made with ImageJ, the open source software from the National Institutes of Health. The step-by-step procedure for dot quantification obtained by ImageJ is illustrated on Figure 12.

\section{Magnetic manipulation of cells: from cell sorting to magnetic targeting in tissue engineering and cell therapies \\ Magnetic cell sorting}

Magnetic cell manipulation that applies to magnetophoresis can also be applied to magnetic cell sorting (Figure 13), where we can separate cells in respect to their magnetic load [38]. This may be particularly advantageous when we want a precise and homogenous iron load within a cell fraction and/or want to eliminate poorly loaded cells that would, for example, be less detectable by MRI or less responsible to magnetic targeting. Moreover, magnetic cell sorting could be used to separate magnetic cells from complex mixtures or to sort cells with respect to their endocytosis capacity.

\section{Impact of the magnetic force}

The effect of magnetic forces on cells will be also tightly related to the fact if the cell is suspended in a liquid or if it adheres on a substrate. While suspended cells more or less freely move when submitted to remote magnetic forces, when we try to magnetically manipulate adhering cells and the magnetic force is lower than the adhesion constraint, the cell cannot move and the magnetic force acts on MNP loaded intracellular endo-lysosomes. Such 


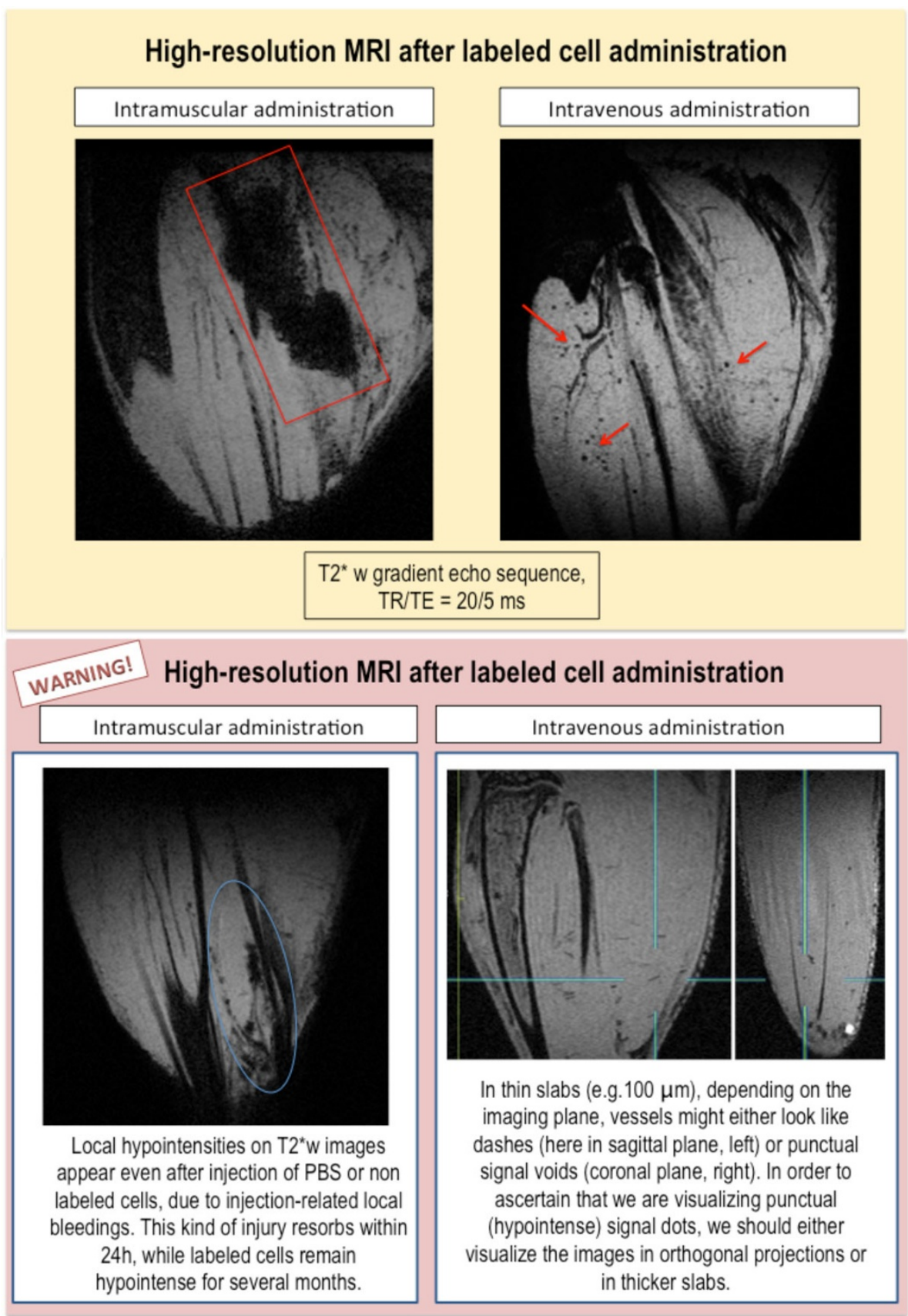

Figure 11 High-resolution of murine hind limbs injected with labeled cells or phosphate saline buffer (PBS) only. Top: mice intramuscularly (left) or intravenously (right) injected with labeled macrophages. Bottom: mice intra-muscularly (left) or intravenously (right) injected with PBS. The images were obtained with a $4.7 \mathrm{~T}$ scanner provided with a dedicated cryogenic probe.

intracellular constraints can be used to deform the cell in a controlled direction and could be used, for example, to control the formation of a vascular network with magnetically labeled endothelial progenitor cells [39]. Magnetic manipulation might allow enhanced cell seeding and engraftment in different scaffolds for tissue engineering [40] and may enable new perspectives for in vitro construction of organized multicellular assemblies and tissue substitutes [41].

\section{Magnetic vectorization: the response to the need for localized cell delivery}

For what concerns magnetic cell manipulation in vivo, a new field of therapeutic delivery- the magnetic vectorization 


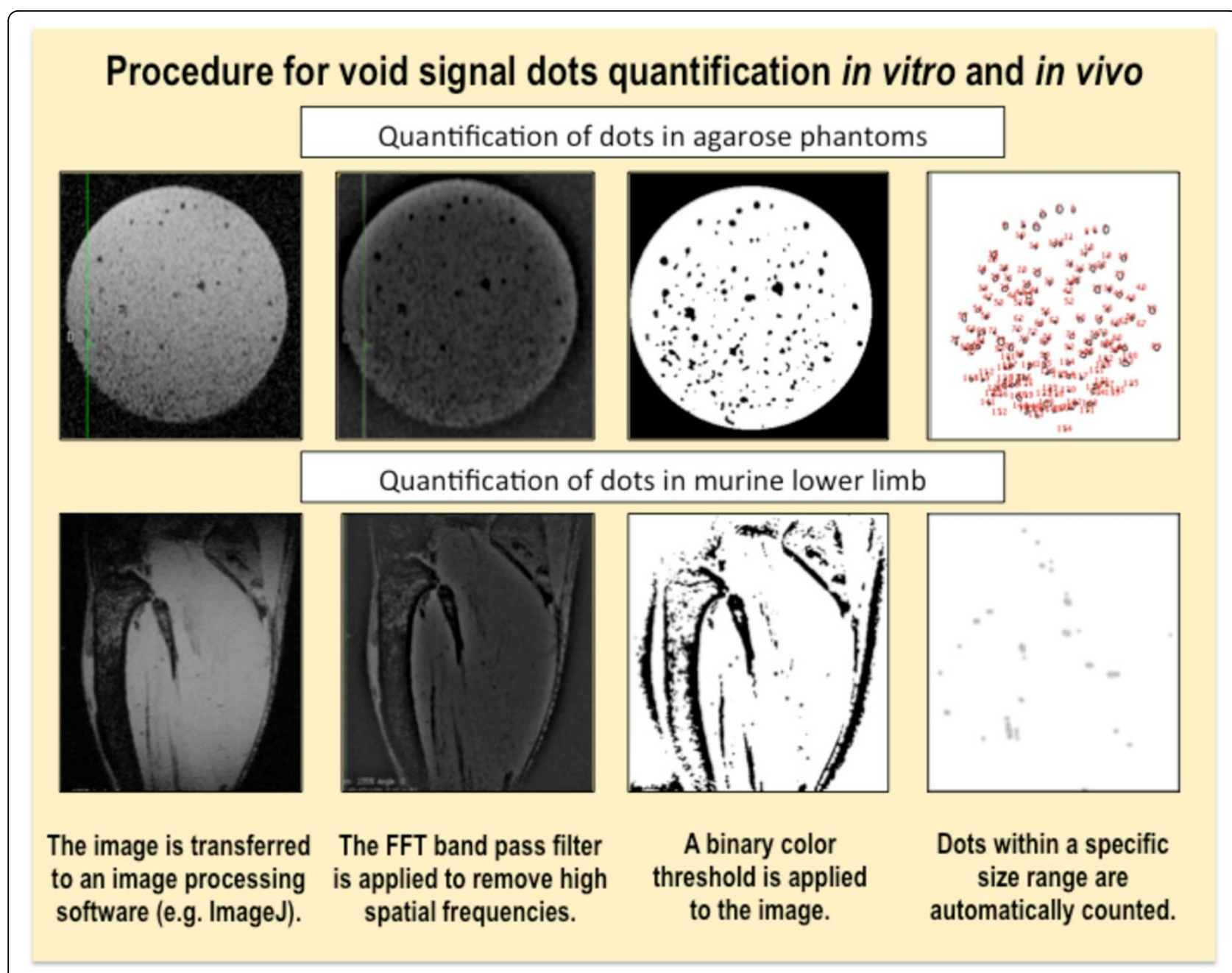

Figure 12 Representation of a simplified procedure for relative dot quantification in vitro and in vivo. Image processing was performed with the open source ImageJ software.

or magnetic targeting of cells is emerging (see Figure 14 for the main objectives and requirements for magnetic cell targeting). This might be particularly interesting for cell guiding in stem cell transplantation for regeneration of injured tissues. Nevertheless while a substantial therapeutic effect was expected from stem cell treatment in acute or chronic cardiac ischemia, the treatment showed moderate therapeutic benefit in preclinical trials. Stem cell transplantation failed to improve the myocardial function, mainly because the majority of injected cells escape from the injured site, due to the local blood flow, which washes away the cells, and cardiac contractions, which squeeze the cells out, leading to poor cell engraftment (generally only less than $10 \%$ of the originally injected cells remain in the injured area). In order to enhance cell retention, some recent studies have proposed magnetic targeting in different cell therapies. However, to date, it is still uncertain if magnetic forces applied to cells would overcome the forces induced by the bloodstream and/or if the cells would still persist in the target place, once the magnet would be withdrawn.

Magnetic vectorization was recently evaluated for cardiac cell transplantation, where magnetically labeled endothelial progenitor cells were injected in the infarcted myocardium while a magnet was externally applied to rats in the heart zone. Magnetically assisted cell delivery resulted in an increased concentration of cells and the short-term effect on cell retention was monitored in vivo by MRI and quantified by RT-PCR [42]. In a study evaluating the long-term engraftment, the functional benefits of magnetically assisted cell retention were also confirmed [43], improving cardiac ventricular function.

\section{Practical aspects for magnetic vectorization}

A first step towards an effective magnetic targeting is to prepare viable magnetic cells, which will be responsive 


\title{
Microfluidic setting for magnetic cell sorting
}

\author{
A) Microfluidic chip with the cell sorting chamber
}

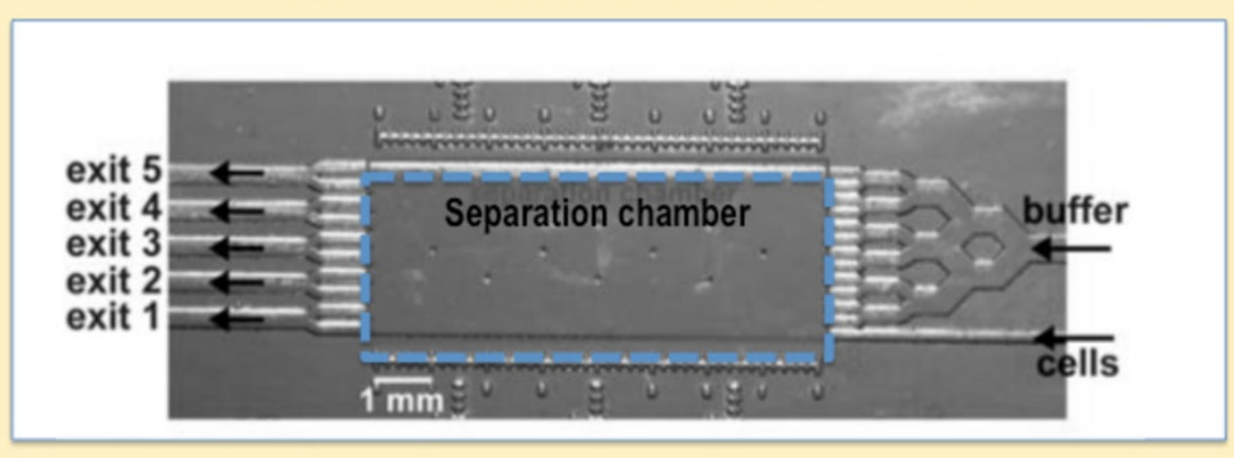

\section{B) Experimental results from macrophage sorting B) Cellular iron load detected by magnetophoresis}
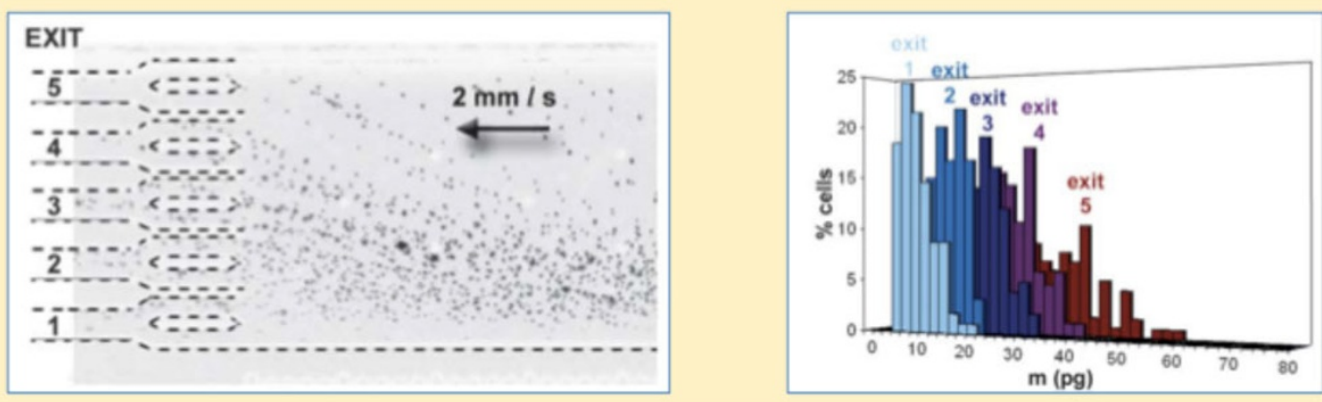

Figure 13 Magnetic cell sorting set-up. A) The photograph of the microfluidic chip showing the cell and buffer inlet, the separation chamber and five exit channels. Within the chamber, each cell population will move towards a specific exit. B) The migration of differently loaded macrophages towards their respective exits is driven by the value of the magnetic field gradient along the cell's trajectory and by the cell's magnetic load. C) The iron load of each cell fraction was quantified by the single-cell magnetophoresis. The figure is adapted from reference (38).

to the given magnetic force. Before any in vivo application, we should therefore assess in vitro the best parameters for the magnetic manipulation of cells (Figure 15). Indeed the conditions in gels are only a poor approximation of what will happen after cell administration to living beings. Anyway, this pre-assessment does, however, allow us to see at least if we reached the minimal magnetization that might enable distal cell guiding. Before we translate cell vectorization to animals, we can also assess how magnet retains cells during the stirring of agarose phantoms. Other approaches might be more complex and can theoretically and experimentally evaluate the effect of cell aggregation after magnetic cell targeting in models simulating vessel bifurcation [44].

Once we endowed cells with sufficient magnetization for cell vectorization, we can proceed to magnetic targeting in vivo (Figure 16). When we disperse labeled cells in the injection medium (which is generally the PBS), magnetic cells tend to be more prone to aggregation than non-labeled cells. If cell aggregates are injected intravenously, they will block the vessels (especially the small pulmonary ones) and the animals will die. In order to thoroughly disperse the cells, it is therefore necessary to disperse cells with a pipette cone or even pump the suspension in and out of the syringe for several times. This procedure might eventually lead to cell lysis, consequently, after such methods of dispersion, we should assess cell viability. If the viability is compromised, we have to disperse and administer cells by a syringe with a smaller gauge number (larger needle diameter). Nevertheless, even if administered cells are individualized, they might, under certain conditions, form perivascular aggregates within the body after magnetic guiding [45]. 


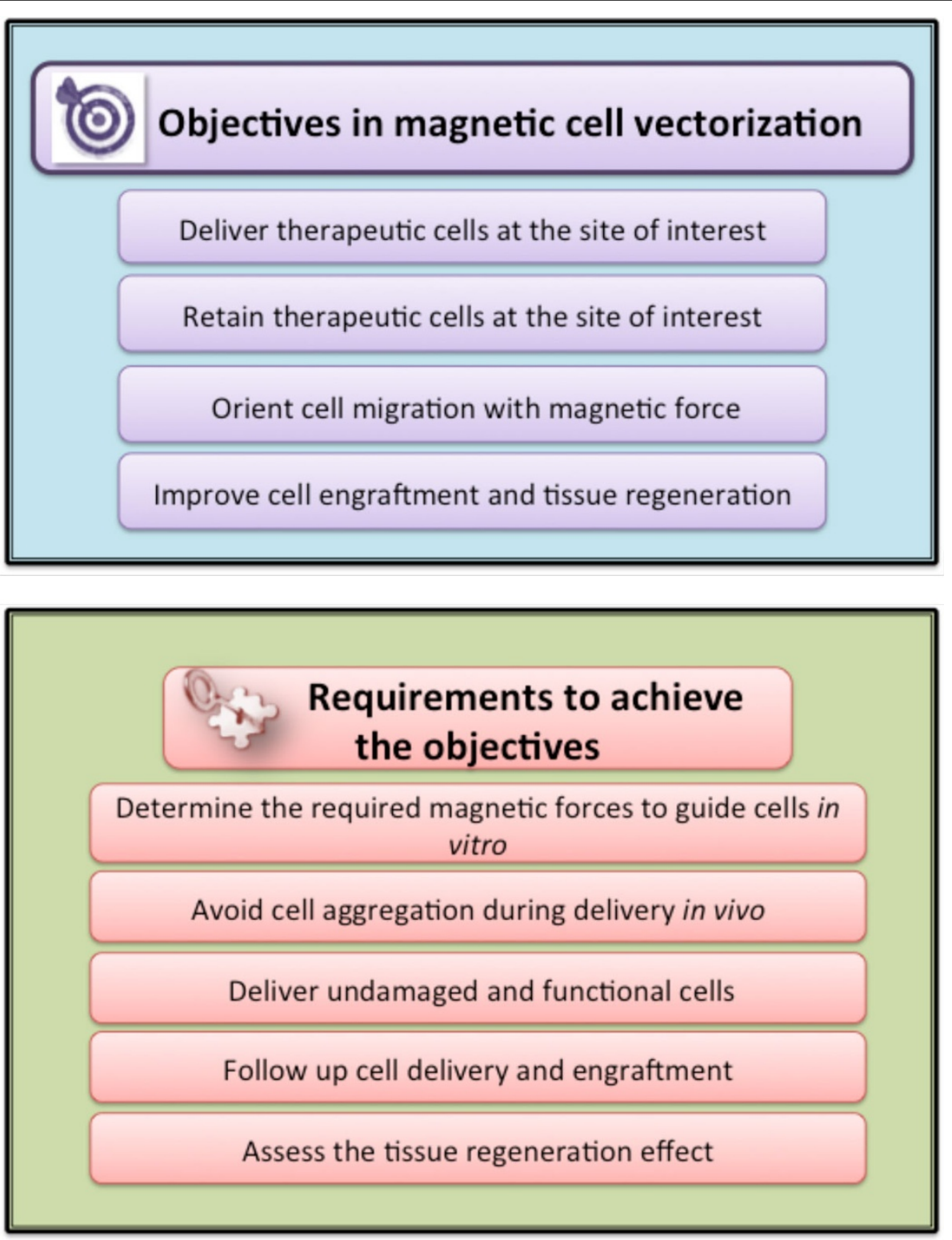

Figure 14 Schematic representation of the objectives and key requirements for magnetic cell vectorization.

As we mentioned in the previous section, MRI allows in vivo follow up of magnetic cells and could be therefore used to confirm successful magnetic cell targeting. Nevertheless, in addition to this method, we should confirm that visualized spots correspond to injected cells. This might be done by immunohistological methods or flow cytometer analysis post mortem. Sometimes, especially if the cells are administered in low concentrations and systemically, the cells are difficult to find both by histology and flow cytometry. If we cannot localize the cells with these or other methods of cell detection, we should at least have a proof of an important therapeutic effect that could serve as a surrogate marker of cell delivery and local action.

\section{Summary and conclusion}

Iron oxide nanoparticles can be used for magnetic labeling of different types of cells. The labeling of living cells allows a variety of biomedical applications ranging from cell manipulation to diagnostics and regenerative medicine. This tutorial provides the basic requirements for efficient cell labeling with anionic (citrate coated) iron oxide nanoparticles and includes sections on troubleshooting to prevent the occurrence of potential cell damage during the labeling procedure. In addition, as single cells can be monitored by high resolution MRI, we provide some appreciation of cellular MRI and present an abridged method for the quantification of 


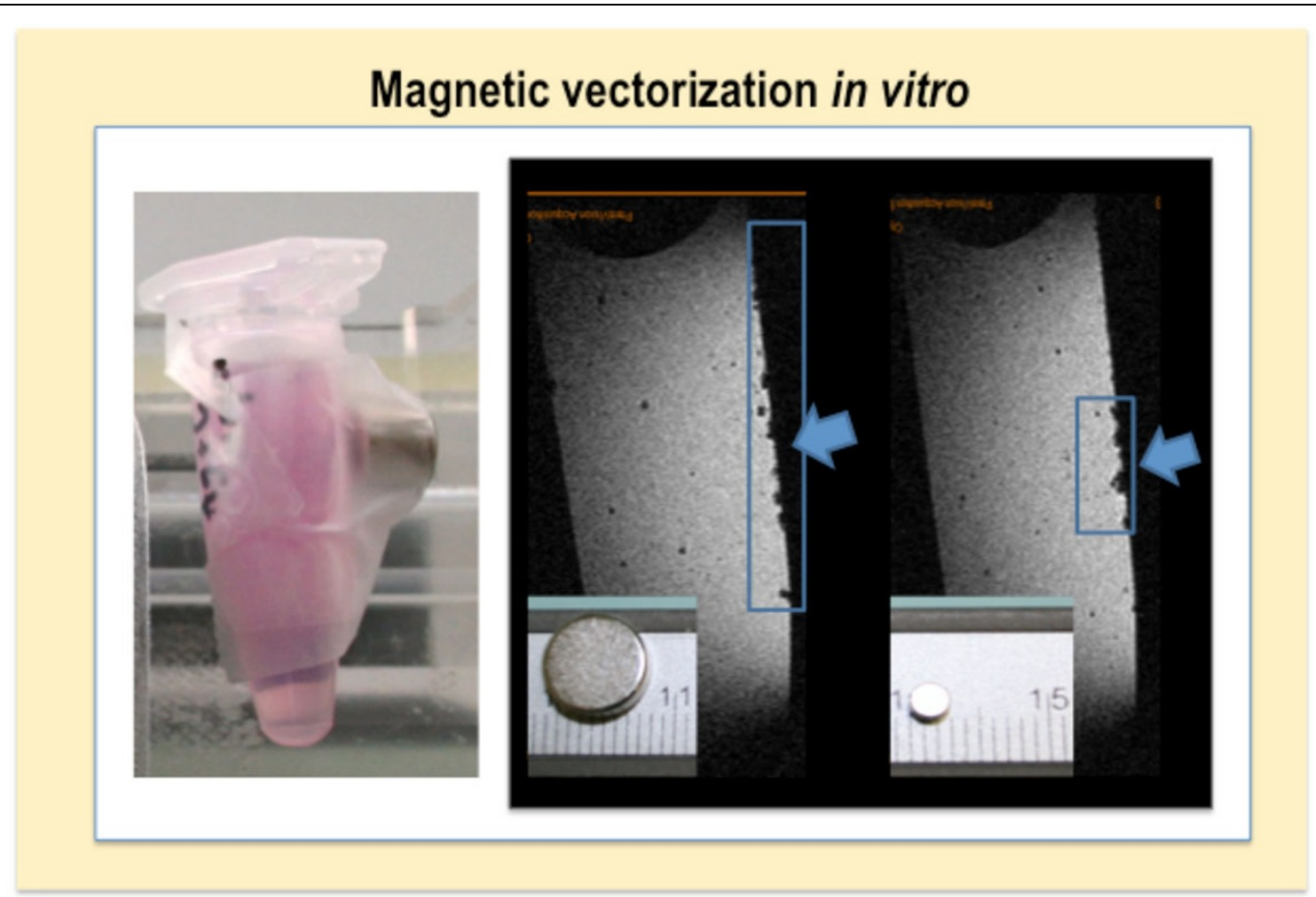

Figure 15 Magnetic vectorization of cells in agarose gels with different magnets. The figure shows the MR scans of two agarose gels, where magnets of different size and strength were put on the tube's surface (left panel). Blue squares and arrows indicate the zone where cells preferentially cumulate due to the applied magnet.

\section{Magnetic vectorization in vivo after i.v. administration of magnetic cells}

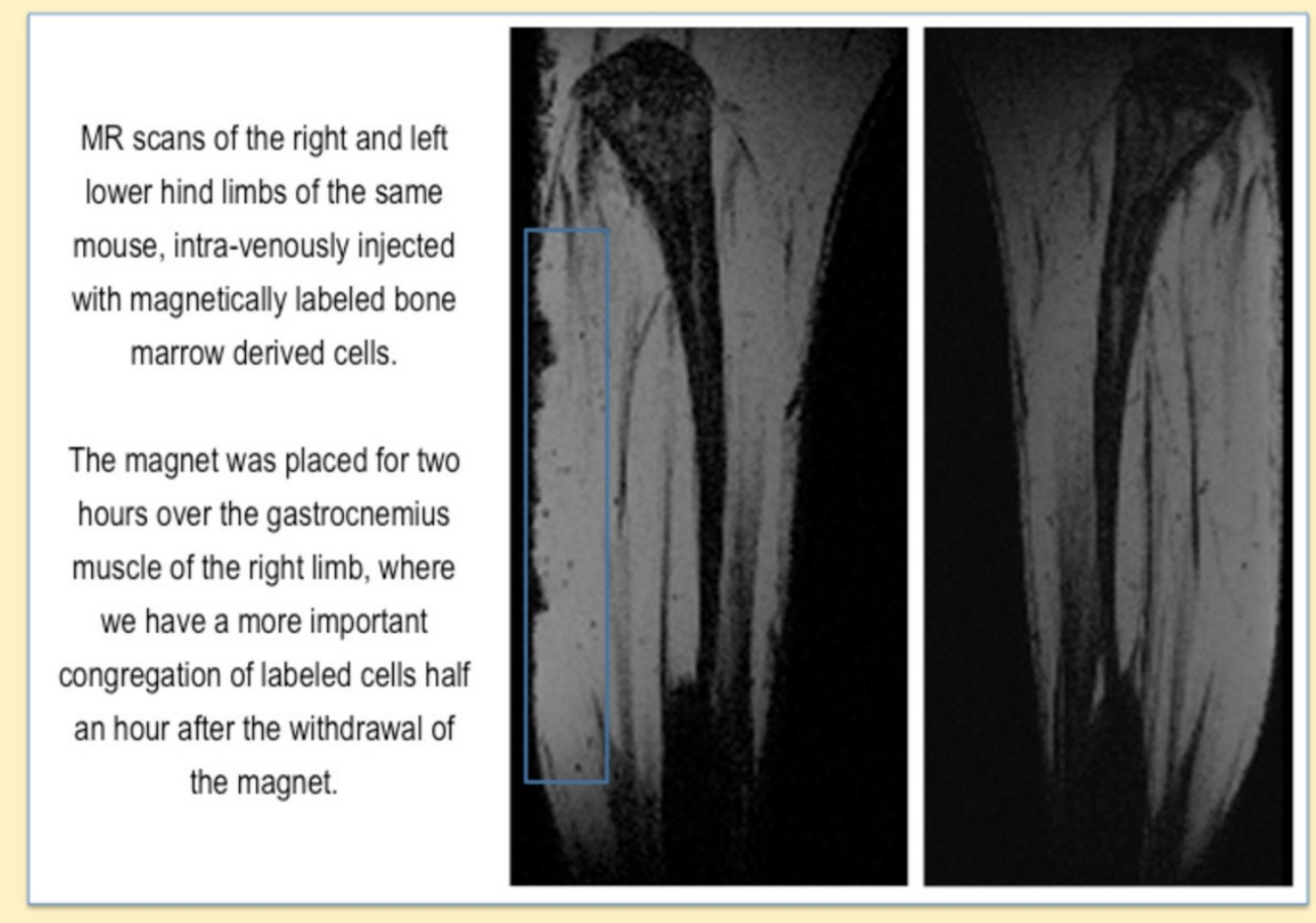

Figure 16 Magnetic vectorization of labeled bone marrow derived cells in a healthy mouse. MR scans showing hind limb scans of an animal. The blue square indicates the zone where cells preferentially cumulate due to the applied magnet. 
punctual signal voids that are generated in vitro and in vivo by labeled cells. Finally, we also assess the potential of cell manipulation that can be exploited both in vitro for tissue engineering and in vivo in cell therapies.

\section{Competing interests}

The authors declare that they have no competing interests.

\section{Acknowledgements}

This article has been published as part of Journal of Nanobiotechnology Volume 11 Supplement 1, 2013: Nanophysics for Health. The full contents of the supplement are available online at http://www.jnanobiotechnology.com/ supplements/11/S1. Publication charges for this tutorial were funded by the CNRS School "Nanophysics for Health", 5 - 9 November 2012, Mittelwhir, France

\section{Authors' details}

'Laboratoire Matière et Systèmes Complexes, UMR 7057, CNRS and Université Paris Diderot, France. ${ }^{2}$ Inserm U970, Paris Cardiovascular Research Center-PARCC/Université Paris-Descartes, France.

Published: 10 December 2013

\section{References}

1. Jones AT, Gumbleton M, Duncan R: Understanding endocytic pathways and intracellular trafficking: a prerequisite for effective design of advanced drug delivery systems. Advanced drug delivery reviews 2003, 55(11):1353.

2. Marion S, Wilhelm C, Voigt H, Bacri J-C, Guillén N: Overexpression of myosin IB in living Entamoeba histolytica enhances cytoplasm viscosity and reduces phagocytosis. Journal of Cell Science 2004, 117(15):3271-3279.

3. Wilhelm C, et al: Intracellular uptake of anionic superparamagnetic nanoparticles as a function of their surface coating. Biomaterials 2003, 24(6):1001-1011.

4. Josephson L, Tung C-H, Moore A, Weissleder R: High-efficiency intracellular magnetic labeling with novel superparamagnetic-Tat peptide conjugates. Bioconjugate chemistry 1999, 10(2):186-191.

5. Montet-Abou K, Montet X, Weissleder R, Josephson L: Cell internalization of magnetic nanoparticles using transfection agents. Molecular imaging 2007, 6(1):1

6. Lynch I, Salvati A, Dawson KA: Protein-nanoparticle interactions: what does the cell see? Nature nanotechnology 2009, 4:546-547.

7. Lartigue Ln, et al: Nanomagnetic sensing of blood plasma protein interactions with iron oxide nanoparticles: impact on macrophage uptake. Acs Nano 2012, 6(3):2665-2678.

8. Fayol D, Luciani N, Lartigue L, Gazeau F, Wilhelm C: Managing Magnetic Nanoparticle Aggregation and Cellular Uptake: a Precondition for Efficient Stem-Cell Differentiation and MRI Tracking. Advanced Healthcare Materials 2012, 2(2):313-325.

9. Wilhelm C Gazeau F: Universal cell labelling with anionic magnetic nanoparticles. Biomaterials 2008, 29(22):3161-3174.

10. Arbab AS, et al: A model of lysosomal metabolism of dextran coated superparamagnetic iron oxide (SPIO) nanoparticles: implications for cellular magnetic resonance imaging. NMR in Biomedicine 2005, 18(6):383-389.

11. Lévy $M$, et al: Degradability of superparamagnetic nanoparticles in a model of intracellular environment: follow-up of magnetic, structural and chemical properties. Nanotechnology 2010, 21(39):395103.

12. Levy $\mathrm{M}$, et al: Long term in vivo biotransformation of iron oxide nanoparticles. Biomaterials 2011, 32(16):3988-3999.

13. Pawelczyk E, Arbab AS, Pandit S, Hu E, Frank JA: Expression of transferrin receptor and ferritin following ferumoxides-protamine sulfate labeling of cells: implications for cellular magnetic resonance imaging. NMR in Biomedicine 2006, 19(5):581-592.

14. Farrell $E$, et al: Cell labelling with superparamagnetic iron oxide has no effect on chondrocyte behaviour. Osteoarthritis and cartilage/OARS, Osteoarthritis Research Society 2009, 17(7):961-967.

15. Kedziorek DA, et al: Gene expression profiling reveals early cellular responses to intracellular magnetic labeling with superparamagnetic iron oxide nanoparticles. Magnetic Resonance in Medicine 2010, 63(4):1031-1043.

16. Arbab AS, Frank JA: Cellular MRI and its role in stem cell therapy. Regen Med 2008, 3(2):199-215.

17. Neri M, et al: Efficient In Vitro Labeling of Human Neural Precursor Cells with Superparamagnetic Iron Oxide Particles: Relevance for In Vivo Cell Tracking. Stem Cells 2008, 26(2):505-516.

18. Cohen ME, Muja N, Fainstein N, Bulte JWM, Ben-Hur T: Conserved fate and function of ferumoxides-labeled neural precursor cells in vitro and in vivo. Journal of Neuroscience Research 2010, 88(5):936-944.

19. Kostura L, Kraitchman DL, Mackay AM, Pittenger MF, Bulte JW: Feridex labeling of mesenchymal stem cells inhibits chondrogenesis but not adipogenesis or osteogenesis. NMR Biomed 2004, 17(7):513-517.

20. Farrell $E$, et al: Effects of iron oxide incorporation for long term cell tracking on MSC differentiation in vitro and in vivo. Biochem Biophys Res Commun 2008, 369(4):1076-1081.

21. Arbab AS, et al: Labeling of cells with ferumoxides-protamine sulfate complexes does not inhibit function or differentiation capacity of hematopoietic or mesenchymal stem cells. NMR Biomed 2005, 18(8):553-559.

22. Henning TD, et al: The influence of ferucarbotran on the chondrogenesis of human mesenchymal stem cells. Contrast Media \& Molecular Imaging 2009, 4(4):165-173.

23. Wilhelm C, Lavialle F, Pechoux C, Tatischeff I, Gazeau F: Intracellular trafficking of magnetic nanoparticles to design multifunctional biovesicles. Small 2008, 4(5):577-582.

24. Luciani N, Wilhelm C, Gazeau F: The role of cell-released microvesicles in the intercellular transfer of magnetic nanoparticles in the Monocyte/ Macrophage system. Biomaterials 2010, 31(27):7061-7069.

25. Silva AA, Wilhelm C, Kolosnjaj-Tabi J, Luciani N, Gazeau F: Cellular Transfer of Magnetic Nanoparticles Via Cell Microvesicles: Impact on Cell Tracking by Magnetic Resonance Imaging. Pharmaceutical Research 2012 29(5):1392-1403, (Translated from English) (in English).

26. Pawelczyk $E$, et al: In vitro model of bromodeoxyuridine or iron oxide nanoparticle uptake by activated macrophages from labeled stem cells: implications for cellular therapy. Stem Cells 2008, 26(5):1366-1375.

27. Pawelczyk E, et al: In Vivo Transfer of Intracellular Labels from Locally Implanted Bone Marrow Stromal Cells to Resident Tissue Macrophages. PLOS ONE 2009, 4(8):e6712, doi:6710.1371/journal.pone.0006712.

28. Wilhelm C, Gazeau F, Bacri JC: Magnetophoresis and ferromagnetic resonance of magnetically labeled cells. Eur Biophys $J$ 2002, 31(2):118-125.

29. Wilhelm C, Riviere C, Biais N: Magnetic control of Dictyostelium aggregation. Physical Review E 2007, 75(4):041906.

30. Darrasse L, Ginefri JC: Perspectives with cryogenic RF probes in biomedical MRI. Biochimie 2003, 85(9):915-937.

31. Faraj AA, et al: Real - time high - resolution magnetic resonance tracking of macrophage subpopulations in a murine inflammation model: a pilot study with a commercially available cryogenic probe. Contrast media \& molecular imaging 2013, 8(2):193-203.

32. Corot $C$, Robert $P$, Idée JM, Port M: Recent advances in iron oxide nanocrystal technology for medical imaging. Advanced drug delivery reviews 2006, 58(14):1471-1504.

33. Billotey $C$, et al: Cell internalization of anionic maghemite nanoparticles: quantitative effect on magnetic resonance imaging. Magnetic resonance in medicine 2003, 49(4):646-654.

34. Lévy M, Wilhelm C, Devaud M, Levitz P, Gazeau F: How cellular processing of superparamagnetic nanoparticles affects their magnetic behavior and NMR relaxivity. Contrast Media \& Molecular Imaging 2012, 7(4):373-383.

35. Smirnov $P$, et al: In vivo single cell detection of tumor - infiltrating lymphocytes with a clinical 1.5 Tesla MRI system. Magnetic resonance in medicine 2008, 60(6):1292-1297.

36. Smirnov $P$, et al: In vivo cellular imaging of lymphocyte trafficking by MRI: A tumor model approach to cell - based anticancer therapy. Magnetic resonance in medicine 2006, 56(3):498-508.

37. Wilhelm C, Cebers A, Bacri JC, Gazeau F: Deformation of intracellular endosomes under a magnetic field. European Biophysics Journal 2003, 32(7):655-660.

38. Robert $D$, et al: Cell sorting by endocytotic capacity in a microfluidic magnetophoresis device. Lab on a chip 2011, 11(11):1902-1910.

39. Wilhelm C, et al: Magnetic control of vascular network formation with magnetically labeled endothelial progenitor cells. Biomaterials 2007, 28(26):3797-3806. 
40. Robert $\mathrm{D}$, et al: Magnetic micro-manipulations to probe the local physical properties of porous scaffolds and to confine stem cells. Biomaterials 2010, 31(7):1586-1595.

41. Fayol D, et al: Use of Magnetic Forces to Promote Stem Cell Aggregation During Differentiation, and Cartilage Tissue Modeling. Advanced Materials 2013, 25(18):2611-2616.

42. Chaudeurge A, et al: Can magnetic targeting of magnetically labeled circulating cells optimize intramyocardial cell retention? Cell Transplantation 2012, 21(4):679-691.

43. Cheng $K$, et al: Magnetic targeting enhances engraftment and functional benefit of iron-labeled cardiosphere-derived cells in myocardial infarction. Circulation research 2010, 106(10):1570-1581.

44. Riegler J, et al: Targeted magnetic delivery and tracking of cells using a magnetic resonance imaging system. Biomaterials 2010, 31(20):5366-5371.

45. Luciani $A$, et al: Magnetic targeting of iron-oxide-labeled fluorescent hepatoma cells to the liver. European radiology 2009, 19(5):1087-1096.

46. Smirnov P, et al: Single - cell detection by gradient echo 9.4 T MRI: a parametric study. Contrast media \& molecular imaging 2006, 1(4):165-174.

doi:10.1186/1477-3155-11-S1-S7

Cite this article as: Kolosnjaj-Tabi et al:: Cell labeling with magnetic nanoparticles: Opportunity for magnetic cell imaging and cell manipulation. Journal of Nanobiotechnology 2013 11(Suppl 1):S7.

\section{Submit your next manuscript to BioMed Central and take full advantage of:}

- Convenient online submission

- Thorough peer review

- No space constraints or color figure charges

- Immediate publication on acceptance

- Inclusion in PubMed, CAS, Scopus and Google Scholar

- Research which is freely available for redistribution

Submit your manuscript at www.biomedcentral.com/submit
C Biomed Central 